\title{
Renovación y reorganización profesional en tiempo de crisis farmacéuticos y veterinarios durante la gripe de 1918-1919 en España*
}

\section{Renovação e reorganização profissional em tempo de crise}

farmacêuticos e veterinários durante a gripe de 1918-1919 na Espanha

\section{Professional renovation and reorganization in time of crisis}

pharmacists and veterinarians during the influenza epidemic of 1918-1919 in Spain**

MARÍA ISABEL PORRAS GALLO

Doctora en Medicina y Cirugía, Profesora Titular de Universidad Unidad de Historia de la Ciencia, Departamento de Ciencias Médicas Facultad de Medicina de Albacete, Universidad de Castilla-La Mancha C/ Almanza, 14. 02006. Albacete. Espanha marialsabel.Porras@uclm.es

RESUMEN En este trabajo se estudia el rol que representaron los farmacéuticos y veterinarios españoles durante la epidemia de gripe de 1918-19 y

* Artigo recebido em: 05/03/2009. Autor convidado.

** Deseo constar mi agradecimiento al profesor Joaquín Sánchez de Lollano de Historia de la Veterinaria de la Universidad Complutense de Madrid y al personal de la Hemeroteca de la Facultad de Veterinaria de dicha universidad, por haberme facilitado la recogida de algunas fuentes empleadas para la elaboración de este trabajo. 
se evalúa en qué medida dicha crisis sanitaria se constituyó en un elemento dinamizador del proceso de renovación y reorganización profesional de dichos sanitarios en España. El estudio muestra cómo a tal fin una parte de los farmacéuticos y, en menor medida, de los veterinarios tomaron como referente el proceder de los médicos de mostrarse como expertos mediante el recurso al laboratorio para gestionar la situación de crisis y aprovecharla para exponer sus viejas demandas profesionales. Frente a esta actitud hubo otra, en la que el papel central lo ocuparon las reivindicaciones de mejoras profesionales sin renunciar a mantener sus funciones tradicionales. Desde esta posición los farmacéuticos responsabilizaron a la epidemia y a las medidas adoptadas de su situación de deterioro y reclamaron de los poderes públicos ayudas para mejorar su posición, mientras que los veterinarios mantuvieron una enérgica labor reivindicativa.

Palabras clave gripe de 1918-1919, farmacéuticos, veterinarios, España

RESUMO Neste trabalho se estuda o papel que os farmacêuticos e veterinários espanhóis representaram durante a epidemia de gripe de 1918-19, e se avalia em que medida esta crise sanitária se constituiu em um elemento dinamizador do processo de renovação e reorganização profissional dos sanitaristas na Espanha. O estudo mostra como uma parte dos farmacêuticos e, em menor escala, dos veterinários utilizaram um procedimento comum entre médicos: fizeram uso do laboratório para administrar a situação de crise, aproveitando a mesma crise para expor antigas demandas profissionais. Além desses, outros reivindicaram melhorias profissionais, sem renunciar a manutenção de suas funções tradicionais. Tomada essa posição, os farmacêuticos colocaram a culpa de sua situação de deterioro na epidemia e nas medidas adotadas, e pediram aos poderes públicos ajuda para melhorar sua situação, enquanto os veterinários mantiveram um trabalho reivindicativo enérgico.

Palavras-chave gripe de 1918-1919, farmacêuticos, veterinários, Espanha

ABSTRACT This paper studies the role that pharmacists and veterinarians played during the influenza epidemic of 1918-19 in Spain, and assesses how this health crisis became an element of the dynamic process of renewal and reorganization of the health professional in Spain. The study shows how a part of the pharmacists and, to a lesser extent, the veterinarians followed the example of the physicians, presenting themselves as "experts" by turning to the laboratory to manage the crisis, and taking advantage of the situation to press long-standing professional demands. There was another contrasting attitude, where the claims for professional improvement occupied centre stage without implying abandonment of their traditional roles. From this position, pharmacists blamed the epidemic and the measures taken against it 
for the deterioration of their situation, and called for government assistance to improve their position, while veterinarians maintained a lively campaign in favour of their demands.

Key words 1918-19's influenza, pharmacists, veterinarian, Spain

\section{Introducción}

Hace unos años Charles Rosenberg llamó la atención sobre el carácter de "drama teatral" que adopta una epidemia en tanto fenómeno social. ${ }^{1}$ Comienza en un momento determinado, tiene lugar en un escenario limitado espacial y temporalmente, continúa en un marco de creciente tensión, dirige inevitablemente hacia una crisis individual y colectiva y, por último, empuja hacia su conclusión. Son muy numerosos los actores que intervienen en esta representación y que, en un momento inesperado y bajo el fantasma de la muerte, deben enfrentarse a una situación de crisis - sanitaria, en principio-y proporcionar una respuesta inmediata. En esas circunstancias, los distintos grupos sociales se ven arrastrados a modificar sus dinámicas habituales y ejecutar distintas acciones de lucha. Además, como indicó también Rosenberg, la brusquedad con la que aparece una epidemia, propicia que se comporte como un corte transversal de la comunidad en la que asienta, que contribuye a poner de relieve los problemas que esa sociedad tenía en el momento en el que estalla la epidemia, pero también aquellos que permanecían latentes y que se manifiestan ante esa situación de crisis. ${ }^{2}$ De ahí el interés y el valor que posee el estudio de una epidemia, especialmente cuando se trata de un caso como es el de la gripe de 191819, que tuvo tan graves consecuencias demográficas y que se desarrolló en una coyuntura crítica marcada por la I Guerra Mundial y por el convencimiento de la ciencia médica de que era capaz de combatir eficazmente cualquier enfermedad infecciosa.

A pesar de todo ello esta pandemia ha sido escasamente estudiada hasta fechas muy recientes. ${ }^{3}$ El renovado protagonismo que la presencia epidémica de la gripe aviar en algunos países asiáticos ha conferido a la pandemia de 1918-1919, ${ }^{4}$ ha propiciado la aparición de una reciente histo-

1 ROSENBERG, Charles E. Explaining epidemics and other studies in the History of Medicine. Cambridge-New York: Cambridge University Press, 1992, p.279.

2 ROSENBERG, Charles E. Explaining epidemics and other studies in the History of Medicine, p.279.

3 Una visión sintética sobre la tradicional falta de estudios sobre la pandemia de gripe de 1918-1919, figura en: HOWARD, Phillips e KILLINGRAY, David. Introduction. In: HOWARD, Phillips e KILLINGRAY, David. (eds.) The Spanish influenza pandemic of 1918-19. New perspectives. London: Routledge, 2003, p.1-25.

4 Algunas de las obras que reflejan esta situación son: STEVENS, Neil. La gripe aviar. Málaga: Editorial Sirio, 2005: PERENNE, Jean-Philippe e BRICAIRE, François. Pandémie. La grande menace. Paris: Fayard, 2005; GARRET, Laurie. The Next Pandemic? Foreign Affairs, v.84, n.4, p.3-23, July/August 2005; OSTERHOLM, Michael T. Preparing for the next pandemic. Foreign Affairs, v.84, n.4, p.24-37, July/August 2005. 
riografía sobre dicha pandemia. ${ }^{5}$ Estos trabajos se han sumado a los que surgieron en los años ochenta e inicios de los noventa del siglo XX impulsados por la aparición del Sida, ${ }^{6}$ así como a los realizados con motivo de la conmemoración del octogésimo aniversario de la pandemia. ${ }^{7}$

Sin restar ningún valor a esta reciente historiografía sobre la denominada Gripe Española, ${ }^{8}$ hay que reconocer que son varios los aspectos a los que no se les ha prestado todavía suficiente atención. Hasta ahora el interés ha estado centrado en analizar fundamentalmente el papel desempeñado por los médicos y las enfermeras, pero no en ocuparse de la labor de otros profesionales sanitarios que también tuvieron protagonismo durante la pandemia. El objetivo del presente trabajo es precisamente poner de relieve cuál fue el rol que representaron los farmacéuticos y los veterinarios españoles durante la epidemia de gripe de 1918-1919 y evaluar en qué medida dicha crisis sanitaria se constituyó en un elemento dinamizador del proceso de renovación y de reorganización profesional de dichos profesionales sanitarios en España. ${ }^{9}$

5 Desde que se inició el siglo XXI los trabajos dedicados a estudiar esta pandemia desde el punto de vista histórico ha crecido enormemente. Una muestra de ello son los 167 resultados que se pueden encontrar en PubMed introduciendo como perfil de búsqueda "1918 influenza", restringiendo la búsqueda temporalmente desde el 1 de enero de 2000 hasta el 1 de enero de 2009 y desde el punto de vista temático a los que figuran dentro del capítulo "history of medicine". Una muestra de los artículos aparecidos en esta década en las revistas histórico-médicas más importantes, figura en: PORRAS GALLO, María Isabel. Sueros y vacunas en la lucha contra la pandemia de gripe de 1918-1919 en España. Asclepio. Revista de Historia de la Medicina y de la Ciencia, v.60, n.2, p.261-288, julio-diciembre 2008. Junto a ello hay que mencionar algunas nuevas monografías como: BERTUCCI, Liane Maria. Influenza, a medicina enferma: ciência e práticas de cura na época da gripe espanhola em São Paulo. Editora UNICAMP, 2004; RICE, G. Black November: the 1918 influenza pandemic in New Zealand. $2^{\text {nd }}$ ed. Christchurch: Canterbury University Press, 2005; JOHNSON, Niall. Britain and the 1918-19 influenza pandemic. A dark epilogue. London/New York: Routledge, 2006; TORRES SILVEIRA, Anny Jackeline. A Influenza Espanhola e a cidade planejada. Belo Horizonte, 1918. Belo Horizonte: Argumentum. La revista História, Ciências, Saúde-Mangunihos ha dado buena cobertura en sus páginas al estudio de la gripe de 1918 en Brasil. Al dossier aparecido en el volumen 12, n.1 de enero-abril de 2005, hay que añadir los trabajos de: SANTOS, R. A. DOS. O Carnaval, a peste e a 'espanhola'. História, Ciências, Saúde-Mangunihos, v.13, n.1, p.129-158, 2006; SOUZA, Christiane Maria Cruz de. The Spanish flu epidemic: a challenge to Bahian medicine. História, Ciências, Saúde - Manguinhos, Rio de Janeiro, v.15, n.4, octubre-dicembre de 2008 (Disponible en http://www.scielo.br).

6 A los trabajos que aparecerán mencionados a lo largo del texto, hay que añadir: BERNABEU MESTRE, Joseph. (coord.) La ciutat davant el contagi. Alacant i la grip de 1918-19. Valencia: Conselleria de Sanitat i Consum/Generalitat Valenciana, 1991; PORRAS GALLO, María Isabel. Una ciudad en crisis: la epidemia de gripe de 1918-19 en Madrid. Madrid: Universidad Complutense de Madrid, 1994. (Tesis doctoral en Medicina). PORRAS GALLO, María Isabel. Una ciudad en crisis: la epidemia de gripe de 1918-19 en Madrid. Madrid: Editorial Complutense, 2002, http://www.ucm.es/eprints/2765/; PORRAS GALLO, María Isabel. Un reto para la sociedad madrileña: la epidemia de gripe de 1918-19. Madrid: Ed. Complutense-CAM, 1997; MARTíNEZ, Manuel. València al Limit. La ciutat davant l'epidemia de grip de 1918. Simat de la Valldigna: Edicions La Xara, 1999. Una extensa relación bibliográfica -aunque no exhaustiva- sobre las aportaciones realizadas en los años ochenta y noventa del siglo XX sobre la gripe de 1918-19 figura en: HOWARD, Phillips e KILLINGRAY, David. (eds.) The Spanish Influenza Pandemic of 1918-19. New perspectivas, p.301-351.

7 Con tal motivo se celebró en Cape Town (Sudáfrica) en septiembre de 1998 una reunión organizada por Howard y Killingray. Algunos de los trabajos allí presentados forman parte de la monografía: HOWARD, Phillips e KILLINGRAY, David. (eds.) The Spanish Influenza Pandemic of 1918-19. Este aniversario ha generado también una literatura sobre la pandemia de 1918, elaborada mayoritariamente por periodistas científicos. Una relación de las principales obras de estas características figura en: PORRAS GALLO, María Isabel. Sueros y vacunas en la lucha contra la pandemia de gripe de 1918-1919 en España, nota 1, p.262.

8 Aunque esta pandemia sea conocida con el calificativo de española, su origen no estuvo en España. Este injusto calificativo se debe a la prensa europea de la época y a nuestra neutralidad en la Gran Guerra.

9 Junto a textos científico-profesionales (memorias, libros, revistas...), se han usado como principales fuentes documentación de archivo e información procedente de la revisión de la prensa general. 


\section{La epidemia de gripe de 1918-1919 en una España convulsa con una clase médica deseosa de alcanzar mayor protagonismo en la sociedad española}

La pandemia de gripe de 1918-1919, la crisis sanitaria más grave del siglo XX hasta la aparición del sida, provocó una honda conmoción en la sociedad contemporánea por sus más de treinta millones de muertes ${ }^{10}$ y su predilección por la población adulta joven, normalmente menos afectados por dicha enfermedad. En España la mayor mortalidad se produjo también entre las personas de 20 a 40 años, y el número total de fallecidos fue de 270.000. Al igual que en otras partes del mundo, la epidemia cursó en tres brotes epidémicos: el primero, en la primavera de 1918; el segundo, en el otoño de ese mismo año, y el tercero, en los primeros meses de 1919. Sin embargo, hubo variaciones locales en cuanto a la presentación de dichos brotes y a su gravedad. De hecho, el mayor número de víctimas se produjo durante el segundo brote en la mayor parte de España, ${ }^{11}$ salvo en la ciudad de Madrid en la que la mayor mortalidad se registró durante el primer brote que tuvo lugar al final de la primavera. ${ }^{12}$

Aunque España no tomó parte en la Primera Guerra Mundial, el bienio 1918-19 estuvo marcado por un estado de crisis política, económica y social, así como por el convencimiento de una parte de los médicos y otras élites de la sociedad española de que el país presentaba un retraso sanitario y científico y era necesario llevar a cabo importantes reformas para corregir dicha situación. Este estado de opinión empezó a cobrar auge a finales del siglo XIX en el marco de las ideas economicistas, nacionalistas y regeneracionistas imperantes. ${ }^{13}$ Entre las medidas que se propusieron figuraron la promulgación de una nueva Ley de Protección de la Salud Pública, adaptada a los principios de la nueva ciencia médica, ${ }^{14}$ y la creación de un Ministerio de Sanidad..$^{15}$ Ninguna de las dos medidas se materializó con anterioridad al desarrollo de la epidemia de gripe de 1918-1919, como consecuencia de

10 Según algunos estudios realizados en las últimas décadas, esta cifra habría sido superior. Se ha estimado en que dicha gripe habría provocado cincuenta o cien millones de muertes. PATTERSON, K. D. e PYLE, G. F. The Geography and mortality of the 1918 influenza pandemic. Bulletin of History of Medicine, v.65, n.1, p.4-21, 1991; JOHNSON, Niall e MUELLER, Juergen. Updating the accounts: global mortality of the 1918-1920 'Spanish' influenza pandemic. Bulletin of History of Medicine, v.76, n.1, p.105-115, spring 2002.

11 ECHEVERRI DÁVILA, Beatriz. La gripe española. La pandemia de 1918-19. Madrid: Centro de Investigaciones Sociológicas-Siglo XXI, p.120-122, 1993.

12 PORRAS GALLO, María Isabel. Una ciudad en crisis: la epidemia de gripe de 1918-19 en Madrid, p.212-239; PORRAS GALLO, María Isabel. Un reto para la sociedad madrileña: la epidemia de gripe de 1918-19, p.52-65; PORRAS GALLO, María Isabel. Las repercusiones de la pandemia de gripe de 1918-19 en la mortalidad de la ciudad de Madrid. Boletín de la Asociación de Demografía Histórica Española, v.14, n.1, p.75-116, 1996.

13 HAUSER, Philip. Madrid bajo el punto de vista médico-social. Madrid, vol.2, p.8-11, 1902 (Se cita por la edición preparada por MORAL, Carmen del, Madrid: Editora Nacional, 1979).

14 MARTín SALAZAR, Manuel. La Sanidad en España. Madrid: Imprenta del Colegio Nacional de Sordomudos y de Ciegos, 1913, p.157-161.

15 Su creación era otra de las reformas pendientes desde que lo solicitó el médico Hauser en 1884. Con posterioridad fueron varias las ocasiones en que se reivindicó sin ningún éxito. HUERTAS GARCÍA-ALEJO, Rafael. El debate sobre la creación del Ministerio de Sanidad en la España del primer tercio del siglo XX. Discurso ideológico e iniciativas políticas. Asclepio, v.XLV, n.1, p.89-122, 1993. 
la inestabilidad política y de la oposición que algunos médicos ejercieron. Lo único que se logró fue la aprobación de la Instrucción general de Sanidad de $1904,{ }^{16}$ medida legislativa importante, pero insuficiente para corregir la problemática sanitaria española. ${ }^{17}$ De ahí que en 1918, cuando estalló la epidemia de gripe, el marco legislativo sanitario era considerado inadecuado, y los asuntos de Sanidad e Higiene Pública seguían dependiendo del Ministerio de la Gobernación. ${ }^{18}$

Conviene recordar también que la Medicina de esos momentos creía estar viviendo una etapa triunfalista frente a la patología infecciosa. La doctrina bacteriológica estaba proporcionando un mejor conocimiento de la etiología de las enfermedades infecciosas y, sobre todo, recursos efectivos frente a ellas. Los médicos se creyeron capaces de controlar este tipo de patologías, que empezaron a denominar "enfermedades evitables". ${ }^{19}$ Este estado de opinión caló también entre los facultativos españoles. De ahí que, cuando comenzó la gripe de 1918-1919, les pareciera viable enfrentarse a la situación epidémica e incluso fuera valorado por algunos como una oportunidad para mostrar su alta capacitación científica y lograr mayor protagonismo en la sociedad española en todos aquellos temas que tuvieran que ver con la salud y la enfermedad, como venían demandando desde finales del siglo XIX.20

\section{Los expertos en proceso de reorganización y renovación afron- tando la epidemia de gripe de 1918-19}

Para comprender mejor la actitud y la posición de los médicos españoles durante la epidemia de gripe de 1918-19, es preciso tener en cuenta que este colectivo se encontraba inmerso en un proceso de reorganización y renovación profesional, iniciado en el trascurso de la Gran Guerra. ${ }^{21}$ Dicho proceso fue el resultado de la concurrencia de dos elementos. El primero de ellos era el convencimiento de que la profesión médica se había desprestigiado, dado que se veían obligados a trabajar gratis o casi gratis y

16 RODRÍGUEZ OCAÑA, Esteban. La asistencia médica colectiva en España, hasta 1936. In: Historia de la acción social pública en España. Beneficencia y previsión. Madrid: Centro de Publicaciones del Ministerio de Trabajo y Seguridad Social, p.321-359, 1990

17 LÓPEZ COMAS, Manuel. Significación y estima de la Instrucción General de Sanidad vigente. Medicina Social Española, 1, p.373-379.

18 Artículo 1 de la Instrucción General de Sanidad. Apud: Gaceta de Madrid, n.22, p.273, 22 de enero de 1904.

19 De esta cuestión, nos hemos ocupado en PORRAS GALLO, María Isabel. La lucha contra las enfermedades 'evitables' en España y la pandemia de gripe de 1918-19. Dynamis, v.14, p.159-183, 1994

20 PORRAS GALLO, María Isabel. Una ciudad en crisis: la epidemia de gripe de 1918-19 en Madrid, p.372-394.

21 PORRAS GALLO, María Isabel. Una ciudad en crisis: la epidemia de gripe de 1918-19 en Madrid, p.372-394. Para contextualizar la situación de los médicos en el marco de la de los profesionales en España, sigue siendo de interés la consulta de: VILLACORTA BAÑOS, Francisco. Burguesía y cultura. Los intelectuales españoles en la sociedad liberal. Madrid: Siglo XXI, p.140-156, 1980; VILLACORTA BAÑOS, Francisco. Profesionales y burócratas. Madrid: Siglo XXI, p.165-186 y 288-346, 1989 
carecían de medidas de protección social, frente a la vejez, etc. ${ }^{22}$ A este elemento se había sumado la creencia de que lograrían un mayor protagonismo social al término de la I Guerra Mundial como consecuencia del profundo cambio que se estaba registrando en todos los órdenes (cultural, político, social, etc.). De hecho, "la valorización del factor hombre" había "sufrido hondísima transformación", ${ }^{23}$ y, como reconocían algunos facultativos, el médico ni podía ni debía ser ajeno a la conmoción producida, ya que "ninguna profesión permite adentrarse en el alma ajena con tan sencilla facilidad como la del médico". ${ }^{24}$

Ahora bien para estar en condiciones de desempeñar adecuadamente ese papel, los médicos necesitaban prepararse, y uno de los primeros pasos era llevar a cabo una campaña de defensa de la clase médica. Partiendo del Colegio de Médicos de Madrid y con el apoyo de Academias y Sociedades científicas, dicha campaña se trasladó también a las Cámaras Parlamentarias, ${ }^{25}$ constituyéndose una Junta de diputados médicos en el Congreso y una Comisión de senadores médicos en el Senado. ${ }^{26}$ Mediante ambas medidas pretendían exponer al Gobierno sus principales reivindicaciones y obtener de éste solución a las mismas. La colegiación obligatoria, la limitación del número de titulados, la aprobación de un nuevo plan de estudios que revalorizara el título de médico y la construcción de una nueva y moderna Facultad de Medicina en Madrid fueron algunas de las demandas efectuadas.

Inmersos en esta campaña de defensa de la clase médica, los médicos españoles se enfrentaron a la epidemia de gripe de 1918-19 con el claro objetivo inicial de mostrar su alto grado de preparación científica. Elaboraron un rico discurso sobre los distintos aspectos de la enfermedad, trataron de servirse del laboratorio para resolver definitivamente el tema de la etiología de la gripe y para poner a punto recursos profilácticos y terapéuticos - vacunas y sueros, respectivamente - verdaderamente específicos y eficaces contra la epidemia. Sin embargo, al igual que ocurrió en otros países, no consiguieron fijar científicamente la etiología de la gripe ni preparar tratamientos y remedios profilácticos verdaderamente eficaces, que sumado a la gran mortalidad de la epidemia, propició que la sociedad española se sintiera defraudada y desconfiara de su condición de expertos. En el marco de esa campaña de defensa profesional en la que se encontraban, los mé-

\footnotetext{
22 JUARROS, César. La opinión de los políticos. Dice Sánchez Guerra. Boletín del Colegio de Médicos de la Provincia de Madrid, n.16, p.1-2, abril de 1917; PÉREZ MORENO, Ezequiel. Carta abierta al Presidente del Colegio de Médicos. Boletín del Colegio de Médicos de la Provincia de Madrid, n.16, p.13-16, abril de 1917.

23 JUARROS, César. La opinión de los políticos. Dice Sánchez Guerra, p.1.

24 JUARROS, César. La opinión de los políticos. Dice Sánchez Guerra, p.2.

25 PÉREZ MORENO, Ezequiel. Carta abierta al Presidente del Colegio de Médicos, p.13-16; Política sanitaria. Boletín del Colegio de Médicos de la Provincia de Madrid, p.9, mayo de 1918; FRANCOS RODRíGUEZ, José. La opinión de un ministro. Boletín del Colegio de Médicos de la Provincia de Madrid, n.17, p.5-6, mayo de 1917.

26 Política sanitaria. Boletín del Colegio de Médicos de la Provincia de Madrid, p.9, mayo de 1918.
} 
dicos optaron por señalar las principales carencias económicas, sociales y sanitarias que España presentaba en esos momentos y relacionarlas con la magnitud que estaba alcanzando la epidemia. ${ }^{27}$ Denunciaron la insalubridad de las viviendas, la escasez y carestía de las subsistencias, la insuficiencia de los recursos sanitarios disponibles, la reglamentación sanitaria inadecuada y la tardía e incorrecta respuesta del poder político. Y, entre otras cosas, demandaron una Ley de Sanidad adecuada, la independencia de los médicos, la creación de un Cuerpo de Sanidad Civil y de un Ministerio de Sanidad, la construcción de un Hospital de epidemias en Madrid y la mejora de las infraestructuras sanitarias. ${ }^{28}$

Esta manera de actuar permitió a los médicos volver a presentar ante la sociedad y los poderes públicos algunas de sus viejas aspiraciones profesionales planteándolas como medidas imprescindibles para evitar situaciones graves como la que se estaba viviendo, pero también tratar de convencer de que la magnitud de la epidemia no se debía a un fracaso de la Medicina ni suyo.

\section{Los farmacéuticos al inicio de 1918: una clase desprestigiada en búsqueda de su renovación}

Las reacciones y actuaciones de los médicos que acabamos de referir se convirtieron en un referente para los farmacéuticos españoles. Estos profesionales sanitarios habían comenzado el año de 1918 con un sentimiento de que "la decadencia de la Farmacia caminaba a pasos agigantados". ${ }^{29}$ Dicha decadencia se pretendió combatir mediante el establecimiento de la colegiación obligatoria a los Colegios Farmacéuticos provinciales. ${ }^{30}$ Esta medida se creía apropiada para que, al igual que estaba haciendo la clase médica, se procediera a la renovación de la profesión farmacéutica. En opinión del presidente del Colegio de Farmacéuticos de Madrid, la ocasión era propicia para ello por cuanto era una "época en que todas las clases" deseaban "regenerarse". ${ }^{31}$

Este estado de ánimo presidió la preceptiva reunión de la Junta Directiva de la Unión Farmacéutica Nacional ${ }^{32}$ de abril de 1918. En ella se decidió

27 Información más detallada, figura In: PORRAS GALLO, María Isabel. Una ciudad en crisis: la epidemia de gripe de 1918-19 en Madrid, p.352-369. PORRAS GALLO, María Isabel. Un reto para la sociedad madrileña: la epidemia de gripe de 1918-19, p.107-108.

28 PORRAS GALLO, María Isabel. Una ciudad en crisis: la epidemia de gripe de 1918-19 en Madrid, p.372-394. PORRAS GALLO, María Isabel. Un reto para la sociedad madrileña: la epidemia de gripe de 1918-19, p.108-109.

29 Colegio Provincial de Farmacéuticos de Madrid. El Monitor de la Farmacia y de la Terapéutica, n.23, p.62-63, 5 de febrero de 1918.

30 Los Colegios Provinciales de Farmacéuticos eran unas asociaciones profesionales, cuya afiliación se convirtió en obligatoria para todos los farmacéuticos que desearan ejercer su profesión en España.

31 Colegio Provincial de Farmacéuticos de Madrid. El Monitor de la Farmacia y de la Terapéutica, p.62.

32 La "Unión Farmacéutica Nacional" era la Federación voluntaria de todos los Colegios Provinciales de Farmacéuticos de España. 
que puesto que ya se había logrado la "colegiación obligatoria", "había llegado el momento de acometer grandes reformas en todos los aspectos profesionales". ${ }^{33}$ Dichas reformas estarían "encaminadas a librar a la clase de los peligros que la amenazan". ${ }^{34}$ ¿Cuáles eran estos peligros? Básicamente, dos: su "decadencia moral", y su "aflictiva y precaria situación". ${ }^{35}$ La mayoría de los farmacéuticos los relacionaba casi exclusivamente con uno de los efectos de la Primera Guerra Mundial: la escasez y carestía de los medicamentos. Aunque para una minoría de farmacéuticos, la situación que estaba padeciendo la profesión dependía también de las dificultades que tenían para adaptarse a los cambios que se estaban registrando en la Farmacia, en la que la industria adquiría un peso cada vez mayor.

Por todo ello se convino en la necesidad de establecer como medidas para lograr urgentemente la reorganización profesional: la adopción de las tarifas que fijaran los Colegios profesionales para los distintos medicamentos y preparados, la no repetición de las recetas sin que hubiera una nueva prescripción médica, la supresión de los escaparates y la disminución del cuarteo. ${ }^{36} \mathrm{El}$ éxito de dichas medidas dependía de que se lograra su seguimiento por todos los farmacéuticos. Se estimó que, de esa manera, "Ios Poderes públicos" verían "que los Farmacéuticos se preocupaban de la salud pública, aún perjudicándose en sus intereses". ${ }^{37}$ Con ello se dignificaría la profesión, pero además, como se expuso en la reunión de la Junta Directiva de la Unión Farmacéutica Nacional, se lograría recuperar "la prosperidad material de la clase farmacéutica"38 de la que ya no gozaban.

Estas eran las condiciones cuando los farmacéuticos debieron hacer frente a la epidemia de gripe de 1918-1919. Como ocurrió con los médicos, su comportamiento durante la crisis sanitaria estuvo marcado por ese sentimiento de decadencia y esa firme decisión de regenerarse como profesión, pero también por el convencimiento que existía a nivel corporativo de que tanto la epidemia como el momento ulterior a la misma eran propicios para esa renovación a la que aspiraban. Este convencimiento quedó muy bien reflejado cuando desde la Unión Farmacéutica Nacional se afirmaba:

33 Junta Directiva en Pleno de La Unión Farmacéutica Nacional. Unión Farmacéutica Nacional. La Farmacia Moderna, n.12, p.98-99, 25 de junio de 1918; Junta Directiva en Pleno de La Unión Farmacéutica Nacional. Unión Farmacéutica Nacional. A los farmacéuticos españoles en ejercicio. La Farmacia Moderna, n.13, p.106-107, 10 de julio de 1918

34 Junta Directiva en Pleno de La Unión Farmacéutica Nacional. Unión Farmacéutica Nacional, p.98-99; Junta Directiva en Pleno de La Unión Farmacéutica Nacional. Unión Farmacéutica Nacional. A los farmacéuticos españoles en ejercicio, p.106-107.

35 Junta Directiva en Pleno de La Unión Farmacéutica Nacional. Unión Farmacéutica Nacional, p.99.

36 Junta Directiva en Pleno de La Unión Farmacéutica Nacional. Unión Farmacéutica Nacional, p.98-99; Junta Directiva en Pleno de La Unión Farmacéutica Nacional. Unión Farmacéutica Nacional. A los farmacéuticos españoles en ejercicio, p.106

37 Colegio Provincial de Farmacéuticos de Madrid. El Monitor de la Farmacia y de la Terapéutica, p.63.

38 Junta Directiva en Pleno de La Unión Farmacéutica Nacional. Unión Farmacéutica Nacional, p.99. 
la epidemia presente preocupa a toda España; y la opinión, la Prensa y las clases directoras prestan preferente atención al problema sanitario, hasta ahora desatendido. Ilustres hombres públicos incorporan con carácter primordial las cuestiones sanitarias al programa político de su partido; la clase médica pide una ley de Sanidad, que con la de Epidemias serán pronto votadas; y el país, justamente alarmado, no se negará a sacrificios que conduzcan a garantir su salud. ¿Cuándo encontrará la clase farmacéutica terreno más abonado para lograr sus justas aspiraciones? ${ }^{39}$

De las palabras que acabamos de reproducir no sólo queda clara la importancia que los farmacéuticos otorgaban a la epidemia como oportunidad para lograr sus aspiraciones, sino también el seguimiento que hacían de las acciones y reivindicaciones de la clase médica, y de cómo las utilizaron como modelo a seguir. Como expondremos seguidamente, podemos hablar de dos posturas o vías básicas adoptadas por los farmacéuticos durante la epidemia con la finalidad de servirse de dicha crisis sanitaria para tratar de modificar la deteriorada imagen que la sociedad española tenía de ellos y lograr esa deseada "regeneración profesional". Así, la Unión Farmacéutica Nacional se mostró partidaria de adoptar una postura más activa, mientras que otros sectores, sobre todo los directores de las principales revistas científico-profesionales, optaron por una actitud en cierta medida más pasiva.

\section{La clase farmacéutica frente a la epidemia de 1918-19. La gran oportunidad para su regeneración y reorganización}

Los que adoptaron esta última actitud trataron de justificar su situación de "desprestigio profesional" por la epidemia, las actuaciones de los poderes públicos e incluso por el comportamiento de la prensa general durante la crisis sanitaria. ${ }^{40}$ Se sirvieron para ello de las páginas de las principales revistas farmacéuticas científico-profesionales. ${ }^{41}$ En vez de dar prioridad en ellas a la elaboración de un discurso científico sobre la gripe, centraron sus esfuerzos en dos cuestiones: la reproducción de las Reales Órdenes y/o Reales Decretos dictados y la descalificación de las medidas adoptadas y/o solicitadas para combatir la epidemia. ${ }^{42}$ Criticaron las actuaciones y propuestas de médicos, políticos y, muy particularmente, de las autoridades sanitarias. Frecuentemente detrás de dichas críticas se escondían intereses

39 Unión Farmacéutica Nacional. Circular a los Colegios. El Monitor de la Farmacia y la Terapéutica, n.833, p.510-512, 15 de noviembre de 1918.

40 FRANCO, J. P. Rumbo que se impone. La Farmacia Española, p.769-773, 5 de diciembre de 1918.

41 Entre estas revistas, cabe mencionar: La Farmacia Moderna, La Farmacia Española, El Monitor de la Farmacia y de la Terapéutica.

42 Entre otras fueron criticadas las siguientes medidas: desinfecciones, créditos extraordinarios, distribución de socorros. PORRAS GALLO, María Isabel. Una ciudad en crisis: la epidemia de gripe de 1918-19 en Madrid, p.450-457. PORRAS GALLO, María Isabel. Un reto para la sociedad madrileña: la epidemia de gripe de 1918-19, p.110-111. 
personales y profesionales. Con esta clave pueden ser interpretadas por ejemplo algunas críticas efectuadas al Inspector General de Sanidad, Manuel Martín Salazar, dada su condición de médico militar y la oposición de los farmacéuticos a la creación de laboratorios y farmacias militares. ${ }^{43}$

El tema estrella de estas descalificaciones fue el Bando que dictó el Gobernador Civil de Madrid sobre el precio de los medicamentos con el fin de conocer las existencias disponibles de una serie de medicamentos y fijar como precio máximo de los mismos el que éstos tenían a primeros de mayo, antes de estallar la epidemia. En todas las revistas se abordó este tema, se reprodujo el bando íntegramente, y se criticó abiertamente, prolongándose la polémica más allá del primer brote. ${ }^{44}$ El Colegio de Farmacéuticos de Madrid llegó a nombrar una Comisión que visitó al gobernador civil de Madrid para manifestar su malestar por dicho bando, que fue interpretado como un claro ataque contra los intereses farmacéuticos, ${ }^{45}$ y sobre todo por el trato que los farmacéuticos estaban recibiendo por parte de la prensa de información general. Desde la Junta Directiva de la Unión Farmacéutica Nacional se criticó la pasividad de los poderes públicos. En su opinión, no sólo no habían llevado a cabo ninguna acción para evitar el alza del precio de los productos que debían adquirir los farmacéuticos, sino que tampoco habían procedido a la importación de los que se carecía por completo. ${ }^{46}$ Se demandaron actuaciones inmediatas similares a las adoptadas en el caso de los artículos alimenticios de primera necesidad. ${ }^{47}$ En esta línea, el Colegio de Farmacéuticos de Madrid, pidió al Ministerio de la Gobernación que el estado hiciera "las gestiones precisas" para combatir la falta de sales de quinina y otros productos farmacéuticos mediante su adquisición desde Inglaterra y Holanda. ${ }^{48}$

Ahora bien, la Unión Farmacéutica Nacional no limitó su papel durante la epidemia a realizar las críticas que hemos comentado, sino que optó por adoptar una postura más activa. En su opinión, se hacía preciso usar dos

43 La creación de laboratorios y farmacias militares era interpretada por los farmacéuticos civiles como un modo de competencia. Sobre esta cuestión, puede consultarse: SIBONI, Luis. Proyecto de Ley de Farmacia. La Farmacia Moderna, n.8, p.85-87, 15 de abril de 1919; Un caso de incompatibilidad. La Farmacia Moderna, n.23, p.223-224, 1919; Otra farmacia militar. La Farmacia Española, n.27, p.425, 1919.

44 Un bando histórico sobre el precio de los medicamentos. El Monitor de la Farmacia y la Terapéutica, p.253-254, 5 de junio de 1918; Un caso de inconsciencia gubernativa. La Farmacia Moderna, n.11, p.90-91, 1918; SIBONI, Luis. Campaña de escándalo. La Farmacia Moderna, n.16, p.137-139, 25 de agosto de 1918; Escrito dirigido al Excmo. Sr. Ministro de la Gobernación. La Farmacia Moderna, n.16, p.139-140, 25 de agosto de 1918; Tasa de algunos medicamentos. La Farmacia Española, n.23, p.357-358, 6 de junio de 1918; El bando del gobernador de Madrid. La Farmacia Española, n.24, p.372-373, 13 de junio de 1918; De Madrid a La Habana. La Farmacia Española, n.27, p.420, 4 de julio de 1918; FRANCO, J. P. Breve comentario. La Farmacia Española, n.28, p.436-437, 11 de julio de 1918; Lamentable campaña. La Farmacia Española, n.33, p.521, 15 de agosto de 1918.

45 Un bando histórico sobre el precio de los medicamentos, p.253-254; Un caso de inconsciencia gubernativa, p.90-91.

46 Unión Farmacéutica Nacional. Circular a los Colegios, p.512; Unión Farmacéutica Nacional. Una instancia sobre la carestía de los medicamentos. El Monitor de la Farmacia y la Terapéutica, n.833, p.511-512, 15 de noviembre de 1918

47 Unión Farmacéutica Nacional. Circular a los Colegios, p.512.

48 PORRAS GALLO, María Isabel. Una ciudad en crisis: la epidemia de gripe de 1918-19 en Madrid, p.453 y $462-463$ 
vías para llevar a cabo la renovación de la profesión. Por un lado, mediante la "reivindicación de sus derechos" ante la sociedad y, por otro, en lo relativo a la "modalidad interna de su ejercicio profesional". Por esta segunda vía se trataba, como indicó J. P. Franco, de que "la clase farmacéutica debe intensificar su cultura científica" y "elevar el tono de sus ideales profesionales" ${ }^{49}$ Como continuaba diciendo este farmacéutico, esta actitud se traduciría "en una notable ampliación de la actividad farmacéutica, y, por ende, en un aumento de la consideración social y en un mejoramiento de la situación económica del farmacéutico". ${ }^{50}$ En opinión de J. P. Franco, la manera de lograrlo era mediante la incorporación de dichos profesionales

a las Academias en donde se debatían cuestiones de ciencias físico-químicas y naturales, de terapéutica y de higiene; a la prensa diaria divulgadora de asuntos científicos, a cuantos palenques sean propicios para la manifestación de sus conocimiento. ${ }^{51}$

Los farmacéuticos que optaron por seguir este camino elaboraron un discurso sobre los distintos aspectos de la enfermedad epidémica, que fue muy escasamente recogido en las principales revistas farmacéuticas. ${ }^{52}$ No hubo una participación como colectivo profesional en estos temas, ${ }^{53}$ sino que se trató más bien de individualidades. Así, Herrero de la Orden, que formaba parte de la Asamblea de Subdelegados de Sanidad como representante de Farmacia, se interesó por la etiología y se mostró partidario de considerar que la epidemia estaba causada por una asociación microbiana (bacilo de Pfeiffer, Micrococcus catarhalis y neumococo). ${ }^{54}$ Aunque hubo otros farmacéuticos que siguieron esta misma senda, el mejor exponente de ella fue César Chicote, director del Laboratorio Municipal de Madrid. Con el paraguas que le daba dicho cargo trató de desempeñar su rol de "experto" al más alto nivel, elaborando un discurso sobre la etiología, el diagnóstico, la profilaxis y el tratamiento de la gripe que expuso en diversos foros. Frente a algunas de las medidas profilácticas adoptadas, Chicote actuó combinando en sus intervenciones sus habilidades de "político" y de "experto" científico. Desempeñando este último rol Chicote centró su defensa en aquellas medidas consideradas más apropiadas para ampliar la

49 FRANCO, J. P. Rumbo que se impone, p.769 y 771.

50 FRANCO, J. P. Rumbo que se impone, p.769 y 771.

51 FRANCO, J. P. Rumbo que se impone, p.771.

52 De hecho, en ellas no se publicó ningún artículo sobre la gripe elaborado por los profesionales sanitarios de nuestro. Tan sólo El Monitor de la Farmacia y de la Terapéutica, a partir de febrero de 1919, reprodujo algunos artículos traducidos -o resúmenes de ellos- de autores foráneos que se centraban fundamentalmente en la profilaxis y en la terapéutica de la gripe. Sobre este tema, se remite a: PORRAS GALLO, María Isabel. Una ciudad en crisis: la epidemia de gripe de 1918-19 en Madrid, p.466 (nota 29).

53 Este hecho se pone de relieve, por ejemplo, al revisar la documentación de la Academia Nacional de Farmacia o la del Colegio de Farmacéuticos de Madrid.

54 Sesión científica extraordinaria del Hospital del Niño Jesús. Revista de Medicina y Cirugía Prácticas, n. 1532, p.239245, 28 de noviembre de 1918. 
actividad del farmacéutico y dotarla de un carácter más científico y, a través de ello, conseguir que aumentara la consideración social y económica de estos profesionales. De ahí, su interés por dedicar tempranamente el laboratorio que él dirigía a la búsqueda y aislamiento del agente responsable de la enfermedad epidémica. Resultado de esa tarea fue la preparación de una vacuna por dicho laboratorio, que se aplicó durante el segundo brote epidémico. Chicote dio cuenta del trabajo realizado en la citada institución y de sus principales hallazgos tanto en la prensa general ${ }^{55}$ como en foros científico-profesionales tales como la Real Academia Nacional de Medicina. ${ }^{56}$ En esta institución científica tuvo una intensa y destacada participación no sólo sobre aspectos profilácticos y terapéuticos, sino también en lo referente a la etiología de la gripe. ${ }^{57}$ Fue precisamente en la Real Academia Nacional de Medicina en donde presentó la vacuna de su laboratorio, que no contenía el esperado germen específico de la gripe, sino un conjunto de ellos relacionados con las complicaciones de dicha enfermedad. ${ }^{58}$ Chicote ofreció la vacuna a todos los médicos que la solicitaran y contó con las figuras más relevantes del momento -como el Doctor Gregorio Marañón (1887-1960)- para su preparación y ensayo. ${ }^{59}$ Sus habilidades de político le sirvieron bien en esta tarea. Contando con el respaldo de los médicos más influyentes animó a los facultativos a realizar "todos los ensayos posibles sobre su eficacia", y a que le dieran "con toda tranquilidad su opinión" con el "único interés" decía "de conseguir algún efecto útil, en la profilaxis o en la terapéutica de la epidemia, sin que me anime ningún estímulo de amor propio ni de interés profesional". ${ }^{60}$ Estas palabras finales de Chicote, sin embargo, no nos deben hacen pensar que él no compartiera o fuera ajeno a la demanda formulada por los farmacéuticos durante la epidemia y al término de la misma de lograr el monopolio de los laboratorios, especialmente de los de sueroterapia y vacunoterapia, frente a los médicos contra los que en ocasiones polemizaron abiertamente. ${ }^{61}$

55 Uno de estos foros fue $A B C$, uno de los diarios madrileños de tirada nacional. Informe del Señor Chicote. $A B C$, p.15, 28 de octubre de 1918.

56 Sesión del 9 de noviembre. Apud: Anales de la Real Academia de Madrid, n.38, p.435-437, 1918

57 Sobre la participación de César Chicote en el debate registrado sobre la etiología de la gripe de 1918, véase: PORRAS GALLO, María Isabel. Una ciudad en crisis: la epidemia de gripe de 1918-19 en Madrid, p.319-320 y 325-327.

58 Para una mejor valoración del rol desempeñado por Chicote y la vacuna del Laboratorio Municipal de Madrid, y un conocimiento de todas las que se pusieron a punto y emplearon en España durante la epidemia, puede consultarse: PORRAS GALLO, María Isabel. Sueros y vacunas en la lucha contra la pandemia de gripe de 1918-1919 en España, p.276-287; PORRAS GALLO, María Isabel. Las vacunas como un medio de establecer una profilaxis pública 'científica' contra la gripe de 1918-1919. In: PERDIGUERO GIL, Enrique; VIDAL HERNÁNDEZ, Josep M. (coords.) Las vacunas: historia y actualidad. Menorca: Institut Menorquí d'Estudis, 2008, p.105-122.

59 Más información sobre este tema, figura In: PORRAS GALLO, María Isabel. Sueros y vacunas en la lucha contra la pandemia de gripe de 1918-1919 en España, p.283.

60 Sesión del 9 de noviembre, p.436-437.

61 Con mayor amplitud se aborda este tema en: PORRAS GALLO, María Isabel. Una ciudad en crisis: la epidemia de gripe de 1918-19 en Madrid, p.453 y 462-463 
Esa dualidad de posiciones de César Chicote como "político" y "experto" científico se puso de relieve muy claramente a la hora de manifestarse frente a una de las medidas adoptadas más fuertemente criticadas: las desinfecciones. Desde su condición de "político", de autoridad sanitaria las justificó "por deberes de disciplina" a pesar de su "escasa eficacia". En su opinión,

en Sanidad, como en la clínica, bien saben todos que es forzoso, en no pocas ocasiones, adoptar medidas reclamadas por la opinión pública, aunque no estén completamente de acuerdo con lo que la ciencia dice. ${ }^{62}$

Sin embargo, pese a estas últimas palabras, el Director del Laboratorio Municipal de Madrid trató de apelar también a su carácter científico y a su uso fuera de nuestras fronteras. De hecho, indicó que tanto los líquidos como los aparatos que se estaban usando para realizar las desinfecciones eran los mismos en todos los países, "incluso en los que tienen los servicios más perfectos". ${ }^{63}$ Sin embargo, hay que decir que esto no era exactamente así, como puso de relieve la Comisión médica que el gobierno envió a Francia a estudiar el desarrollo de la epidemia allí y las medidas que se estaban adoptando. ${ }^{64}$ Quizás los aparatos y los líquidos tenían las mismas características, pero su uso fue mucho menor que en España. ${ }^{65}$ Por otro lado, era evidente la escasa o nula efectividad de las desinfecciones o del aislamiento, que Chicote justificó como consecuencia del hacinamiento de la población y de las malas condiciones de los domicilios particulares. ${ }^{66}$

Como he adelantado, desde esa postura más activa se juzgaba necesario complementar esas actuaciones como científicos expertos con una campaña de reivindicación de sus derechos que les permitiera lograr la renovación de la profesión farmacéutica. De ahí que a lo largo de la epidemia e incluso al término de la misma, este colectivo profesional fue concretando sus reivindicaciones. Su interés se centró fundamentalmente en aquellas cuestiones que consideraban les podían proporcionar mayores cotas de actuación, de prestigio y de poder. A tal fin, en la Asamblea extraordinaria de la Unión Farmacéutica Nacional del 19 de mayo de 1919, se tomaron los siguientes acuerdos: el reforzamiento de la autoridad de los Colegios Farmacéuticos provinciales; la asimilación de la clase farmacéutica a la clase médica en la Sanidad Civil; lograr la prioridad de los farmacéuticos "para el desempeño de las plazas técnicas de los Laboratorios químicos e

62 Sesión del 16 de noviembre. Apud: Anales de la Real Academia de Madrid, n.38, p.478-479, 1918

63 Sesión del 16 de noviembre, p.479.

64 La Comisión enviada a Francia por el gobierno español estuvo integrada por los médicos Gregorio Marañón, Gustavo Pittaluga y A. Ruiz Falcó.

65 MARAÑÓN, Gregorio; PITTALUGA, Gustavo e RUIZ FALCÓ, A. Informe sobre el actual estado sanitario de Francia y su identidad con la epidemia gripal en España. El Siglo Médico, Madrid, n.65, p.916-921, octubre de 1918.

66 Sesión del 16 de noviembre, p.480. 
Institutos de Higiene", etc. ${ }^{67}$ Al igual que ocurrió con los médicos, algunas de estas demandas, así como que el Estado abonara las deudas que los Ayuntamientos habían contraído con los farmacéuticos y que el Estado se hiciera cargo del pago de los farmacéuticos titulares, ya habían sido objeto de reivindicación con anterioridad a la epidemia. ${ }^{68}$

A la vista de lo expuesto no es descabellado plantear que uno de los mayores anhelos de los farmacéuticos como colectivo profesional era aumentar su participación en la nueva Sanidad Civil, que se estaba diseñando, y conseguir su total equiparación con los médicos. Los farmacéuticos deseaban tomar parte en la reforma sanitaria y se sintieron defraudados porque las modificaciones introducidas en la organización sanitaria del país en enero de 1919 no les otorgaron un mayor papel a ellos. ${ }^{69}$ Tampoco estuvieron conformes con su exclusión de las reuniones celebradas con el ministro de la Gobernación al objeto de diseñar "un completo plan de reformas". ${ }^{70}$ Igualmente se mostraron contrarios a que los médicos, conscientes de la importancia que habían cobrado la sueroterapia y la vacunoterapia en el tratamiento de la gripe y en el abordaje de otros procesos respiratorios, decidieran monopolizar su fabricación mediante la creación de numerosos laboratorios bajo su exclusiva dirección. ${ }^{71}$ Es cierto que en algún caso se incluyó entre su personal a algún farmacéutico para cumplir en cierta medida con la legalidad vigente, ${ }^{72}$ pero esto disentía claramente de lo defendido por la clase farmacéutica que consideraba "suyo el campo todo en el que han de desenvolverse las actividades" de estos laboratorios. ${ }^{73}$ Se suscitó una amplia polémica que trascendió las páginas de las principales revistas farmacéuticas y alcanzó las de la prensa general. ${ }^{74}$ Lo que estaba detrás de dicha polémica era una delimitación de territorios y de cotas de poder entre médicos y farmacéuticos en cuestiones de Salud Pública, cuya importancia

67 Relación de los acuerdos adoptados en la Asamblea extraordinaria de la Unión Framcéutica Nacional. La Farmacia Española, n.17, p.260, 10 de junio de 1919.

68 Unión Farmacéutica Nacional. La Farmacia Moderna, n.3, p.27-28, 10 de febrero de 1919.

69 SIBONI, Luis. ¿Reformas sanitarias o reparto del presupuesto sanitario? La Farmacia Moderna, n.18, p.217-219 25 de septiembre de 1919.

70 SIBONI, Luis. ¿Reformas sanitarias o reparto del presupuesto sanitario?, p.217-219. SIBONI, Luis. El último plagio de la temporada. La Farmacia Moderna, n.20, p.245-246, 25 de octubre de 1919.

71 Entre los laboratorios de estas características que se crearon, cabe mencionar el Instituto de Biología y Sueroterapia (IBYS), dirigido por el prestigioso parasitólogo Gustavo Pittaluga, o el Instituto dirigido por Jorge Francisco Tello (uno de los directores del Instituto Nacional de Higiene) y por Jorge Ramón. A ellos habría que sumar muchos más, repartidos por algunos puntos de la geografía española. SIBONI, Luis. Renovación y regeneración sanitarias. La Farmacia Moderna, n.14, p.403-404, 25 de julio de 1919. La actividad de algunos de ellos se prolongó a lo largo de la mayor parte del siglo XX, como ocurrió con el IBYS.

72 Tras la epidemia de gripe se aprobaron el Real Decreto de 10-X-1919 y la Real Orden de 27-X-1919 para regular la producción de sueros y vacunas. RODRÍGUEZ NOZAL, Raúl e GONZÁLEZ BUENO, Antonio. Entre el arte y la técnica. Los orígenes de la fabricación industrial del medicamento. Madrid: Consejo Superior de Investigaciones Científicas, p.365-383, 2005. El RD de 10-X-1919 no fue bien recibido por los farmacéuticos por entender que la dirección de los laboratorios encargados de la producción de sueros y vacunas les debía corresponder a farmacéuticos y veterinarios, pero no a los médicos.

73 FRANCO, J. P., ¿Rectificación?... No satisface. La Farmacia Española, n.31, p.484-486, 1 de noviembre de 1919.

74 Para efectuar el seguimiento de esta polémica, véase: PORRAS GALLO, María Isabel. Una ciudad en crisis: la epidemia de gripe de 1918-19 en Madrid, p.463 y 471 (se remite al lector a las fuentes indicadas en la nota 61). 
se había puesto de relieve con motivo de la epidemia de gripe. Ahora bien, como veremos seguidamente, en este reparto también querían entrar los veterinarios.

En un ambiente como el descrito se propuso desde algunos sectores médicos la constitución de un Sindicato Sanitario Único. ${ }^{75}$ Dicha propuesta encontró opiniones favorables, pero también en contra, mostrándose en general un cierto recelo entre los farmacéuticos ante dicha iniciativa. ${ }^{76}$ En este último sentido se mostró J. P. Franco, quien manifestó que

si el acuerdo que se intenta ha de tener probabilidades de viabilidad, hay que determinar previamente, con toda precisión, lo que pertenece a cada una de las tres profesiones sanitarias en el orden profesionalmente propiamente dicho, y hasta qué límites ha de extender su campo cada una de ellas en las cuestiones de higiene y sanidad públicas. ${ }^{77}$

\section{La veterinaria en vías de renovación con anterioridad al desarrollo de la epidemia de gripe de 1918-19}

A la vista de las palabras que acabamos de reproducir parece evidente que la experiencia de la epidemia de gripe de 1918-19 había reavivado las tensiones existentes entre las tres profesiones sanitarias desde finales del siglo XIX para tratar de delimitar claramente los territorios y competencias de cada una de ellas en materia de Sanidad e Higiene Públicas. Y es que, al igual que los médicos y los farmacéuticos, los veterinarios se encontraban también en una fase de renovación iniciada con anterioridad al estallido de la epidemia de gripe. Para un sector de la profesión la vía regia para ello era trabajar dentro del paradigma bacteriológico e incorporar el laboratorio a la actividad veterinaria. ${ }^{78}$ Con ello pensaban poder alcanzar no solamente el ideal científico sino también una mejor consideración social. Ahora bien, proceder de esa manera no era una tarea fácil ni exenta de problemas. De hecho, la Bacteriología no se incorporó a la formación de los veterinarios hasta el plan de estudios de 1912. Tampoco fue sencilla la incorporación

75 Y se invitó a los farmacéuticos a formar parte del mismo. De hecho, Fernando Coca, Secretario del Comité Ejecutivo de Defensa de la Clase Médica, dirigió una carta al presidente del Colegio de Farmacéuticos de Madrid el 2 de diciembre de 1919 para comunicarle que "la Asamblea de Juntas directivas de Colegios de Médicos, [le había] designado para formar parte del Comité Ejecutivo de Defensa de las Clases Sanitarias", razón por la que le rogaban que asistiera a la reunión en la que se consituiría dicho Comité. Archivo de la Real Academia de Farmacia. Legajo 162.11.

76 Luis Siboni, director de la revista La Farmacia Moderna, fue uno de los que mostró recelo a la sindicación de los profesionales sanitarios. SIBONI, Luis. Breves observaciones sobre la última Asamblea. La Farmacia Moderna, n.21, p.260-263, 10 de noviembre de 1919; SIBONI, Luis. Sindicación de las clases médicas. La Farmacia Moderna, n.21, p.263-264, 10 de noviembre de 1919

77 FRANCO, J. P. Hacia el Sindicato Sanitario único. La Farmacia Española, n.36, p.561-562, 20 de diciembre de 1919.

78 GUTIÉRREZ GARCÍA, José Manuel. El impacto del laboratorio en la renovación de la veterinaria española: el caso Joaquim Ravetllat i Estech (1871-1923). Medicina e Historia, n.4 (cuarta época), p.1-15, 2007. Parte de este artículo se ha utilizado como guía para elaborar este apartado sobre la situación de los veterinarios antes de la pandemia de gripe de 1918. 
del laboratorio al estudio de la fisiología y la patología animal. No obstante, desde los primeros años del siglo XX algunos dirigentes de la profesión veterinaria trataron de desterrar "la imagen clásica del veterinario, muy apegada todavía a la medicina equina, al forjado y colocación de herraduras y a la práctica de sangrías". ${ }^{79}$ Con esa misma finalidad se llegó incluso a plantear un cambio de nombre de la profesión, que reflejara más claramente sus aspiraciones a desempeñar un rol importante en asuntos de Salud Pública. Dicha demanda se reavivó con motivo de la discusión del plan de estudios de 1912, pero no llegó a triunfar.

Como han mostrado recientes estudios, ${ }^{80}$ la renovación de la Veterinaria y su reorientación hacia temas de Salud Pública y problemas de los animales de producción era la vía más idónea y casi obligada para poder hacer frente al momento crucial en el que se encontraba esta profesión, como consecuencia de la sustitución de los caballos - principal cliente de los veterinarios - por los vehículos de motor. Estas condiciones de incertidumbre se reflejaron en un endurecimiento de las condiciones de vida de los veterinarios y en un descenso del número de estos profesionales en activo, pero también en un declive del número de alumnos dispuestos a comenzar unos estudios de futuro bastante incierto.

Por otro lado, aquellos veterinarios que se habían entregado a las investigaciones microbiológicas comenzaron a aportar datos que posibilitaban ir aumentando el listado de enfermedades, que en realidad eran zoonosis. Estas investigaciones y sus resultados permitían justificar la intervención de un nuevo experto el "veterinario científico y de laboratorio", que podía ser competitivo frente a otros profesionales sanitarios en el desempeño de algunas tareas de Salud Pública. ${ }^{81}$ Ahora bien, estos intentos de afirmación del rol del veterinario en el terreno de la Salud e Higiene Públicas chocaron frontalmente con la supremacía que la clase médica venía detentando en el ámbito de la Microbiología. De ahí que, como denunciaron frecuentemente los veterinarios y ha sido señalado recientemente por Gutiérrez García, las autoridades político-sanitarias españolas solicitaban "con toda naturalidad el criterio médico en aquellas cuestiones referentes a la ganadería" o en otros temas que los veterinarios consideraban de su incumbencia. ${ }^{82}$ Las quejas por esta situación y las demandas de cambio solicitadas por la profesión veterinaria se pueden seguir al revisar las páginas de las principales revistas veterinarias de carácter científico-profesional, poniéndose de relieve algunas ocasiones en las que se exacerbaban las críticas contra el intrusismo médico y las demandas por obtener parcelas de actuación para la profesión

79 GUTIÉRREZ GARCÍA, José Manuel. El impacto del laboratorio en la renovación de la veterinaria española, p.5.

80 Información sintética sobre este tema, referida no sólo al caso español, figura en: GUTIÉRREZ GARCíA, José Manuel. El impacto del laboratorio en la renovación de la veterinaria española, p.6.

81 GUTIÉRREZ GARCÍA, José Manuel. El impacto del laboratorio en la renovación de la veterinaria española, p.7.

82 GUTIÉRREZ GARCÍA, José Manuel. El impacto del laboratorio en la renovación de la veterinaria española, p.7. 
veterinaria. Una de estas situaciones ocurrió en 1911 con motivo de la elaboración y presentación de un proyecto de bases para la promulgación de una nueva Ley de Sanidad. La denuncia vino de parte de Dalmacio García Izcara, catedrático en la Escuela de Veterinaria de Madrid. En su opinión, el nuevo proyecto concedía la supremacía casi absoluta a la clase médica en las cuestiones de higiene pública, y postergaba o prescindía de veterinarios y farmacéuticos, inclusive para desempeñar tareas que eran de su exclusiva competencia. ${ }^{83}$ García Izcara se mostró muy indignado por ello e indicó que no había ningún otro país en el que se diera una situación parecida.

Sin embargo, a pesar de las manifestaciones de García Izcara, es preciso indicar que unas condiciones similares se daban en Gran Bretaña. Allí la clase médica trató también de acceder al campo de las enfermedades de los animales. ${ }^{84}$ Por el contrario en países como Alemania y Francia la situación era radicalmente distinta, ya que desde mediados del siglo XIX se había instaurado una enseñanza científica rigurosa para los estudiantes de veterinaria, que les permitía constituirse en capacitados investigadores de laboratorio al término de sus estudios. ${ }^{85}$

Lo expuesto hasta ahora permite tomar conciencia de las peculiaridades que confluían en la profesión veterinaria española en los años que precedieron al desarrollo de la epidemia de gripe de 1918-19 y sus principales diferencias con respecto a la situación profesional de los farmacéuticos. Esa aproximación de la veterinaria española al modelo británico más que al alemán o francés, determinó que, aunque una minoría centró su actividad en tratar de reproducir este último modelo, los líderes profesionales optaron por planificar una estrategia de defensa del colectivo veterinario, que estuvo basado principalmente en tratar de lograr una autonomía y dignidad profesional que permitiera la reconstrucción de la profesión y la liberación del intrusismo médico.

\section{La actuación de los veterinarios durante la epidemia de gripe de 1918-1919}

Esta doble manera de afrontar la renovación de la profesión permite explicar también el comportamiento de los veterinarios durante la epidemia de gripe de 1918-1919. La revisión de las páginas de sus principales revistas científico-profesionales ${ }^{86}$ durante el bienio de la crisis sanitaria muestra la

83 GARCÍA IZCARA, Dalmacio. Informe del Colegio Oficial de Veterinarios de la provincia de Madrid a la Comisión del Senado que entiende en el Proyecto de bases para una Ley de Sanidad. Revista de Higiene y Sanidad Veterinaria, n.1, p.87-97, 1911.

84 GUTIÉRREZ GARCÍA, José Manuel. El impacto del laboratorio en la renovación de la veterinaria española, p.7-8.

85 GUTIÉRREZ GARCÍA, José Manuel. El impacto del laboratorio en la renovación de la veterinaria española, p.8.

86 Se han revisado las siguientes revistas: La Semana Veterinaria, Revista de Higiene y Sanidad Veterinaria, Revista de Higiene y Sanidad pecuarias, Revista Veterinaria de España y La Veterinaria Española. 
práctica ausencia de artículos dedicados a ocuparse de los distintos aspectos y características de la gripe (etiología, diagnóstico, profilaxis y tratamiento). Tan solo en mayo de 1918, cuando el primer brote estaba presente en Madrid, se publicó un artículo en el que se revisaba la vacunoterapia a partir de un artículo publicado en 1916 y se concluía señalando que dicha medida había introducido una mejora en el abordaje de las enfermedades, pero no se mencionó en ningún momento la gripe. ${ }^{87}$

Hubo que esperar al segundo brote de la epidemia en el otoño de 1918 para contar con alguna aportación de esa minoría de veterinarios que había optado por trabajar en el marco de la doctrina bacteriológica, que dinamizó el debate existente sobre la etiología de la gripe. Así, Dalmacio García Izcara en la sesión del 12 de noviembre de 1918 de la Real Academia Nacional de Medicina se mostró partidario de considerar que el agente específico de la gripe era un "virus filtrable". ${ }^{88}$ En este mismo sentido se manifestó el director del Laboratorio Municipal de Barcelona, Ramón Turró (1854-1926). ${ }^{89}$ Estas posiciones fueron de las más atrevidas en ese nuevo marco bacteriológico y contrastan con las sustentadas en los únicos dos artículos aparecidos en las principales revistas veterinarias revisadas, en los que se hizo una mención a la epidemia que se estaba padeciendo. Uno de ellos es el que el Profesor Sugrañes, Subdelegado del Cuerpo de Veterinarios municipales, publicó en el apartado de "Estudios de Patología comparada" de la revista La Veterinaria española. Bajo el título Algunas observaciones y medidas preventivas contra la gripe, este veterinario afirmaba que la influenza estaba producida por el bacilo de Pfeiffer y, al mismo tiempo, informaba que asociado a dicho bacilo encontraban frecuentemente otros gérmenes patógenos, principalmente neumococos y estreptococos. Se mostraba partidario de considerar la gripe una enfermedad exclusivamente humana y, en consecuencia, disentía de los que opinaban que pudiera transmitirse desde los animales al hombre. En su opinión, el bacilo de Pfeiffer tenía únicamente un efecto tóxico y mortal en algunos animales de laboratorio (cobayas, conejo común y rata) como se había demostrado experimentalmente. Defendía como medidas profilácticas el aislamiento de los enfermos, la limpieza individual y colectiva, ejercicio moderado al sol, la evitación de aglomeraciones, etc., poniendo el énfasis en las medidas individuales. En ningún momento, Sugrañes efectuaba ningún comentario crítico frente a la nueva ciencia bacteriológica, ni a las medidas adoptadas para combatir la epidemia.

87 Vacunoterapia. Revista de Higiene y Sanidad pecuarias, n.5, p.350-368, 1918.

88 PORRAS GALLO, María Isabel. Una ciudad en crisis: la epidemia de gripe de 1918-19 en Madrid, p.324 y contenido de la nota 118.

89 RODRÍGUEZ OCAÑA, Esteban. La grip a Barcelona: un greu problema esporàdic de salud publica. Epidèmies de 1889-90 i 1918-19. In: Cent anys de Salut Publica a Barcelona. Barcelona: Institut Municipal de la Salut, p. 131-156, 1991. 
Por el contrario, en el otro artículo, firmado bajo el pseudónimo "Un veterinario rural" y con el título de Profilaxis de las enfermedades infecciosas y parasitarias, ${ }^{90}$ se efectuaba una crítica abierta a las medidas adoptadas por las autoridades sanitarias como la desinfección, el aislamiento individual y "otros medios ilusorios, desacreditados ante la ciencia", cuya ineficacia se había puesto de relieve en la lucha contra la epidemia que se estaba sufriendo. El anónimo "veterinario rural" reconocía el fracaso de las investigaciones bacteriológicas y consideraba que la causa de la epidemia era "completamente desconocida". ${ }^{11}$ De ahí que en su opinión para prevenir su aparición había que atender

al aseo corporal, a la cantidad y calidad de los alimentos y a la escrupulosa inspección de los mismos, factores indispensables para establecer no sólo la profilaxis de la gripe, sino la de todas las enfermedades infectocontagiosas y parasitarias. ${ }^{92}$

Tras esta enumeración de medidas preventivas el autor del artículo se iba ocupando de cada una de ellas, de señalar su importancia y el rol que en ellas podían desempeñar los veterinarios, afirmando finalmente que la inspección sanitaria de los alimentos era

de la exclusiva competencia del profesor veterinario, pero no de aquel Veterinario que, en época no muy lejana, ocasionaba la hilaridad del público ignorante (...), sino del profesor moderno, culto y consciente de sus deberes y de la alta misión que en la sanidad pública le corresponde. ${ }^{93}$

Como continuaba diciendo más adelante,

el profesor veterinario moderno es un facultativo capacitado, y aun cuando el plan de enseñanza de su carrera no ha llegado todavía a encajarse dentro del campo que exigen las orientaciones modernas, dispone de elementos modernos para especializarse en conocimientos de Biología, Microbiología, Higiene, Inspección substancias alimenticias, etc, con la intensidad adecuada para cumplir con acierto las funciones que en orden a esas materias se le encomiendan..$^{94}$

De hecho, esa idea había sido apoyada en la IV Asamblea Nacional de Veterinaria, en un reciente discurso en el Senado y "por medio de campañas sostenidas continuamente por propios y extraños en revistas profesionales y rotativos", en los que sin cesar se pidió "que la veterinaria sea elevada a

90 Un veterinario rural. Profilaxis de las enfermedades infecciosas y parasitarias (I). La Veterinaria Española, n.2198, p.481-486, 31 de diciembre de 1918

91 Un veterinario rural. Profilaxis de las enfermedades infecciosas y parasitarias (I), p.481.

92 Un veterinario rural. Profilaxis de las enfermedades infecciosas y parasitarias (I), p.481.

93 Un veterinario rural. Profilaxis de las enfermedades infecciosas y parasitarias (I), p.481, 482-483.

94 Un veterinario rural. Profilaxis de las enfermedades infecciosas y parasitarias (I), p.483. 
facultad y el médico veterinario sea considerado como factor esencial en el mejoramiento de la salud pública y de la riqueza pecuaria". ${ }^{95}$

Efectivamente, esa campaña de defensa profesional de los veterinarios en la línea señalada en este artículo ocupó de manera exclusiva las páginas de la mayoría de las principales revistas veterinarias. Como indicó A. Guerra, director de La Veterinaria española. Revista profesional y científica, se dio prioridad a la publicación de trabajos en los que se efectuaba una defensa de los intereses profesionales. ${ }^{96}$ Esos trabajos se ocuparon de los temas más candentes que coincidieron durante el desarrollo de la epidemia de gripe, pero no hicieron ninguna alusión a la crisis sanitaria ni trataron de servirse de ella para apoyar sus demandas. Fueron varios los artículos en los que se criticaron las reformas docentes que se querían realizar para establecer además una carrera abreviada -"de herradores de tres años"- por entender que ello supondría una desvalorización aún mayor del rol del veterinario en la sociedad española, ${ }^{97}$ pero también un atentando a los intereses económicos de los veterinarios. ${ }^{98}$ Se reclamó insistentemente un plan docente que permitiera el paso de Escuela Veterinaria a Facultad de Veterinaria y que entrañara una formación de mayor calidad científica a los veterinarios para que fueran más competitivos en el ámbito de la Salud e Higiene Públicas y pudieran liberarse del intrusismo médico. ${ }^{99}$ Ríos de tinta corrieron también para quejarse de ese intrusismo médico ${ }^{100}$ y para solicitar la unidad de los veterinarios y la creación, siguiendo el ejemplo de los farmacéuticos, de La Federación Nacional Veterinaria. ${ }^{101} \mathrm{E}$ incluso se llegó plantear la creación de una "Federación de las tres clases sanitarias" especialmente dirigida a buscar una entente cordial entre los miembros de las tres profesiones con actividad en el medio rural para delimitar las competencias y ámbitos de actuación de cada una de ellas y mejorar su situación. ${ }^{102}$

95 Un veterinario rural. Profilaxis de las enfermedades infecciosas y parasitarias (I), p.483

96 Un veterinario rural. Profilaxis de las enfermedades infecciosas y parasitarias (I), p.481.

97 GUERRA, Ángel. I. Numerosos telegramas. II El proyecto de ley de Epidemias. III. Próximas reformas docentes en Veterinaria. La Veterinaria Española, n.2182, p.225-228, 31 de mayo de 1918. GUERRA, Ángel. I. Reformas docentes aprobadas. II. Los herradores de tres años. III Petición incomprensible. La Veterinaria Española, n.2184, p.257-260, 20 de junio de 1918. MORELLÓ, José. Los seudo-veterinarios. La Veterinaria Española, n.2192, p.385-386, 30 de septiembre de 1918

98 FERNÁNDEZ GALLEGO, Luis. Extracto de lo acordado por los Veterinarios del distrito de Belchite (Zaragoza), en la reunión celebrada por los mismos el día 14 de agosto. La Veterinaria Española, n.2189, p.337-338, 15 de agosto de 1918. Laudables acuerdos de un Colegio. La Veterinaria Española, n.2191, p.369-370, 15 de septiembre de 1918. SALDAÑA y SICILIA, G. Peligros de una proyectada reforma. La Veterinaria Española, n.2191, p.370-374, 15 de septiembre de 1918. FERNÁNDEZ, Aproniano. Maremagnum y confusión. La Veterinaria Española, n.2192, p.386-389, 30 de septiembre de 1918.

99 GUERRA, Ángel. I. Numerosos telegramas. II El proyecto de ley de Epidemias. III. Próximas reformas docentes en Veterinaria. La Veterinaria Española, n.2182, p.227. SALDAÑA y SICILIA, G. Peligros de una proyectada reforma, p.370-374.

100 A modo de ejemplo, véase: GUERRA, Ángel. Justificación de una retirada. La Veterinaria Española, n.2189, p.338345, 15 de agosto de 1918.

101 FERNÁNDEZ GALLEGO, Luis. Extracto de lo acordado por los Veterinarios del distrito de Belchite (Zaragoza), en la reunión celebrada por los mismos el día 14 de agosto, p.338.

102 VIDAL, Gedeón. Bases para una Federación profesional. La Veterinaria española, n.2182, p.194-196, 10 de mayo de 1918. En este artículo se exponían las condiciones y requisitos para llevar a cabo la Federación de las tres clases sanitarias. 
Ahora bien, como mostró el anónimo "Veterinario rural" en su artículo, era posible servirse de la epidemia de gripe de 1918-19 para poner de relieve la capacitación científica de los veterinarios para poder desarrollar también un rol de expertos en ciertos temas de Salud e Higiene Públicas y para plantear sus viejas aspiraciones profesionales de una forma más eficaz. ${ }^{103}$ De hecho, como admitió el director de la revista La Veterinaria Española, la publicación de dicho artículo primeramente en La Acción el 25 de noviembre de 1918 había contribuido "muy poderosa y eficazmente en la sanción del reciente reglamento de Mataderos" 104 que venía a responder a ciertas demandas de la profesión veterinaria de cara a lograr su renovación y reorientación. Como hemos visto, esta vía había sido utilizada por los médicos y una parte de los farmacéuticos la había tomado como modelo para la defensa y renovación de su profesión.

\section{Conclusiones}

A la vista de lo expuesto en las páginas precedentes es evidente el papel que la epidemia de gripe de 1918-19 desempeñó como dinamizador de los procesos de renovación y reorganización profesional, que ya habían iniciado los farmacéuticos y los veterinarios españoles con anterioridad al inicio de dicha crisis sanitaria. Tomando como referente la vía adoptada por los médicos con ese mismo objetivo, farmacéuticos y veterinarios diseñaron y llevaron a cabo sus propias estrategias. En ambos casos se advierte el peso que se fue otorgando a la incorporación del laboratorio y la investigación bacteriológica en la modernización profesional, como una vía para ser competitivos en los temas de Salud e Higiene Públicas y estar en condiciones de liberarse del "intrusismo médico".

La crisis sanitaria propició que se hicieran más evidentes las tensiones entre las distintas clases sanitarias, pero también que se hicieran planteamientos para mediante la creación de una Federación de las tres clases sanitarias o de un Sindicato Sanitario Único se buscara una entente entre las tres profesiones sanitarias para gestionar los temas de Salud e Higiene Públicas.

103 UN VETERINARIO RURAL. Profilaxis de las enfermedades infecciosas y parasitarias (I), p.481-486.

104 Ángel Guerra lo indicaba en la nota 1 del artículo: Un veterinario rural. Profilaxis de las enfermedades infecciosas y parasitarias (I), p.481. 